\title{
Taking Cues from the Government: Heuristic versus Systematic Processing in a Constitutional Referendum ${ }^{1}$
}

\author{
De Angelis Andrea ${ }^{\mathrm{a}}$, Colombo Celine ${ }^{\mathrm{b}}$, and Davide Morisi ${ }^{\mathrm{c}}$ \\ ${ }^{a}$ Department of Political Science, University of Lucerne, Lucerne, Switzerland; ${ }^{b}$ Department of \\ Political Science, University of Zurich, Zurich, Switzerland; ${ }^{c}$ Collegio Carlo Alberto, Turin, Italy
}

\begin{abstract}
One of the main criticisms of direct democracy is that it places excessive demands on voters. Are citizens competent enough to vote directly on policy issues? When stakes are high, do citizens mainly follow elites' signals or do they decide in line with their issue preferences? This article addresses these questions in a multimethod setting by combining observational and experimental data from an original three-wave panel survey conducted during the 2016 Italian constitutional referendum. In particular, Finite Mixture Models are employed to model voters' heterogeneous strategies of information processing. Findings show that heuristic voting based on government evaluation prevails over policy-related voting. More specifically, less politically sophisticated and partisan voters relied on government assessment as a heuristic, while sophisticated and independent voters based their decisions mostly on their assessment of the reform. Implications for the question of citizens' competence in direct democracy are discussed.
\end{abstract}

Keywords: Political psychology; referendum voting; dual process theory; Finite Mixture Models; survey experiment

$\dagger$ Corresponding author: Andrea De Angelis (andrea.deangelis@unilu.ch). The Version of Record of this manuscript has been published and is available in West European Politics, 20 June 2019, http://www.tandfonline.com/10.1080/01402382.2019.1633836. 


\section{$1 \quad$ Introduction}

Referendums place high demands on citizens, ${ }^{2}$ as they need to decide over complex policy matters at the ballot box. Indeed, doubts about voter competence constitute the most frequent criticism of direct democracy (Lupia and Matsusaka 2004; Achen and Bartels 2016) and as the use of direct democratic votes increases around the democratic world (Trechsel 2006; Altman 2010; Ruth, Welp, and Whitehead 2017), the question of citizen competence in direct democracy becomes ever more relevant.

Constitutional reforms, which are submitted to referendum votes with increasing frequency (Tierney 2012), pose a particular challenge to direct democracy. First, they entail wide-ranging and fundamental changes impacting on the future of a country. Second, they demand thoughtful deliberation on institutional arrangements, which are hardly comprehensible and distant from citizens' everyday life (Chambers 2001). However, literature shows that political knowledge is generally low, interest in politics is marginal for a large share of the electorate, and political attitudes are often incoherent and unstable (e.g. Converse 1964; Delli Carpini and Keeter 1996; Zaller 1992). How can such an uninformed citizenry decide over complex policies at the ballot box?

In this article, we propose that voters might use the psychological process of attribute substitution, by which individuals tend to substitute complex questions, which require high cognitive effort, with a simpler and more familiar question, to which the answer is more easily accessible. Specifically, we investigate the substitution of the actual ballot question with less demanding and more visible manifestations of the political conflict, such as the assessment of the current government and the prime minister. This mechanism has also been termed 'second-order' voting by scholars of EU

\footnotetext{
${ }^{2}$ In this paper we use 'referendum' and 'direct democratic vote' interchangeably to designate legislative decisions taken by citizens directly through the ballot box, and not by elected representatives.
} 
referendums (e.g. Franklin, Eijk, and Marsh 1995; Glencross and Trechsel 2011, Hobolt 2016; Ivaldi 2006; Siune, Svensson, and Tonsgaard 1994). In direct-democratic consultations, do voters decide on the basis of readily-available heuristics, such as the evaluation of the government, or do they engage in systematic processing of the content of referendum proposals?

The 2016 Italian constitutional referendum represents one of the most salient and controversially debated referendums of the recent years. It concerned a comprehensive constitutional reform that was strongly supported by Prime Minister Renzi. ${ }^{3}$ As result of a clear victory of the "No-camp", the Prime Minister resigned. We argue that this referendum represents an ideal test for heuristic versus systematic political reasoning. On the one side, the reform proposed the most far-reaching transformation of the constitution since the birth of the Italian republic, which incentivises voters' policy-learning efforts. On the other side, the close ties with the political fate of the Prime Minister offered clear and widely available heuristic cues.

We propose an innovative multi-method strategy combining a three-wave panel survey with an embedded survey-experiment. In the observational study we apply Finite Mixture Models, FMMs (Everitt and Hand 1981; Imai and Tingley 2012; Titterington, Smith, and Makov 1985), to tackle theoretical heterogeneity and estimate the share of voters consistent with each theory. In the experimental study, we manipulate arguments and heuristic cues to identify their causal effects on the vote. Our results indicate that heuristic reasoning based on government assessment prevailed over

\footnotetext{
${ }^{3}$ The reform aimed at increasing the efficiency of the law-making process by substantially reducing the role of the Senate, and leaving only the Chamber of Deputies in charge of most legislative matters. After a few months of intense political campaign, on 4 December 2016 a majority of the voters (59 per cent) rejected the prospect of amending the constitution.
} 
detailed policy-assessment. Moreover, different decision-making patterns characterised different types of voters, with less sophisticated voters and anti-government partisans mostly relying on government evaluation as a decision-making heuristic.

\section{Attribute Substitution and Heuristic Reasoning in Constitutional Referendums}

Understanding how citizens make their decisions in direct democracy is essential to assess the quality of these decisions. Ideally citizens would examine the relevant information regarding the policy, consider its pros and cons, and ultimately reach an informed conclusion (Hobolt 2007; Kriesi 2005; Lupia and Matsusaka 2004). However, as a large literature on political sophistication suggests (e.g. Delli Carpini and Keeter 1996), this ideal account may prove unrealistic. Our aim in this study is to investigate how referendum decisions are empirically made, without prematurely dismissing popular voting altogether, as some scholars recently seem to suggest (Achen and Bartels 2016, Brennan 2016).

Cognitive psychologists have argued that individuals who are confronted with cognitively complex questions, often tend to substitute the complex question with an easier one, which they can more readily answer (Kahneman and Frederick 2002; Shah and Oppenheimer 2008). This process of attribute substitution has been shown to take place also in political reasoning (Sunstein 2005; Healy and Lenz 2014; Druckman 2015). In the case of a constitutional referendum proposed by the government, voters might substitute the ballot question with a more familiar question for which they have the answer ready - whether they support or oppose the government who proposes these changes. In this sense, voters use their assessment of the current government as a heuristic for decision making (Hetherington 2007; Kriesi 2005; Lupia 1994; Lupia, McCubbins, and Popkin 2000; Popkin 1991). In the context of direct democratic votes, the use of heuristic cues has been shown to substitute for 
thorough information search and consideration of policy arguments while still leading to reasonable decision-making (Lupia 1994; Christin, Hug, and Sciarini 2003; Kriesi 2005).

Along a similar line of argument, voters can use heuristics for orienting their vote in political arenas they are not familiar with. Scholars refer to EU integration referendums as 'second-order elections', in which voters do not 'truly' express their opinion on EU integration, but rather their satisfaction or dissatisfaction with the current domestic government - a question that is more familiar and easy to answer (Franklin, Eijk, and Marsh 1995; Garry, Marsh, and Sinnott 2005; Glencross and Trechsel 2011; Hobolt 2016; Ivaldi 2006; Leduc 2012; Siune, Svensson, and Tonsgaard 1994; Svensson 2002). This approach draws on the more general theory of second-order elections (Reif and Schmitt 1980), according to which voters use domestic considerations to inform a European vote (Franklin, Eijk, and Marsh 1995). This mechanism is particularly likely when the referendum question is posed by the government in order to gather support for their own policy (Hug 2002) - as was the case in Italy. Scholars found evidence for similar second-order voting patterns in a range of EU-related referendums. For example, Hobolt's (2016) analysis of the Brexit referendum, and Glencross and Trechsel's (2005) analysis of four national referendums on the European Constitution Treaty, conclude that both voters' issue-related attitudes towards the European Union (first-order attitudes) as well as voters' assessment of domestic political actors (second-order voting) affected their decisions.

In so-called dual process models of reasoning, such heuristic reasoning is contrasted with more systematic reasoning, based on detailed information search and consideration of different arguments (Chaiken 1980; Kahneman 2013; Petty and Cacioppo 1986). Indeed, recent studies suggest that in direct democratic decisions, reliance on policy arguments is less uncommon than suspected by critics of direct democracy (Boudreau and MacKenzie 2014; Bullock 2011; Colombo and Kriesi 2017). When policy arguments are available, voters often rely on those arguments to make their decisions and, what 
is more, they are often familiar with the main arguments of the campaign (Colombo 2016). Additional studies show that campaign arguments can affect voting decisions substantially in direct democracy (Christin, Hug, and Sciarini 2003; Hobolt 2005), especially when referendum proposals involve considerable uncertainty (Morisi 2016).

These models assume generally that individuals are motivated to hold accurate opinions, but at the same time they follow the least-effort principle - that is they are motivated to reach a satisfying level of accuracy with as little effort as possible. Highly motivated and/or able individuals will form their opinions in a more systematic way, based on consideration of policy information than less motivated and/or able individuals, who might simply use their government assessment as a shortcut. In our view, the 2016 Italian constitutional referendum represents an ideal case for testing heuristic and systematic political reasoning. On the one side, the reform entailed the proposal for a radical transformation of the Italian political system, that should trigger at least some policy-learning effort. On the other side, the reform was closely tied to the political faith of Prime Minister Matteo Renzi, thereby offering voters' clear, and widely available heuristic cues ${ }^{4}$. From these considerations, we derive our first two competing hypotheses:

H1a: As the Italian constitutional referendum represents a major and very consequential political question, we expect voters to base their decision mainly on the policy content of the reform (Systematic Processing Hypothesis).

\footnotetext{
${ }^{4}$ Appendix A offers a more detailed account of the Italian constitutional referendum.
} 
H1b: Because Prime Minister Renzi tied his fate closely to the constitutional referendum, we expect voters to base their decision mainly on their personal evaluation of the Renzi government as a heuristic cue (Heuristic Processing Hypothesis).

While in our theoretical model and in our hypotheses the heuristic and the systematic way are described as two separate mechanisms of information processing, in reality it is not easy to separate the two mechanisms as they often interact and rather build a continuum than two separate modes of information processing (Chaiken 1980, Petty and Caccioppo 1986). For our study this means that the agreement with policy arguments could be influenced to a certain extent by respondents' evaluations of the Renzi government, or in other words, that they might learn from their trusted political elite actor which the most persuasive arguments are (see e.g. Colombo and Kriesi 2017 for some evidence of this process in referendum campaigns). It is important to keep this caveat in mind, but at the same time we can still make a reasonable distinction between voters who rely more directly on arguments and voters who rely more directly on their attitude towards the government. The experimental element of our study is motivated by the aim to make a clearer analytical distinction between the government heuristic and the systematic argument processing mechanisms.

\subsection{The moderating role of political knowledge and partisanship}

Political knowledge on the constitutional reform might act as a moderator of the decision process, as only citizens who dispose of the necessary knowledge are able to form a considered, issue-based opinion in the first place. Since early studies on public opinion, political knowledge has been treated as one, if not the major determinant of political reasoning (Delli Carpini and Keeter 1996). Indeed, numerous studies have shown the relevance of political knowledge as a moderator of voters' decision- 
making (Barabas, Jerit, Pollock, and Rainey 2014; Jerit, Barabas, and Bolsen 2006; Slothuus and de Vreese 2010; Zaller 1992). Finding that voters with less political information have a higher probability to vote based on their government support would indicate that government support actually serves as a heuristic cue, substituting more complex referendum contents - and not as a strategic means used by well-informed voters. This finding would support existing evidence showing that political cues influence especially those who are less politically sophisticated (Kam 2005; Lau and Redlawsk 2001). On this basis, we formulate the following hypothesis:

H2. Voters with greater factual political knowledge are more likely to vote based on the content of the reform, while less sophisticated voters will vote based on the government heuristic.

With regard to our experimental study, $\mathrm{H} 2$ predicts that a cue explicitly mentioning the government will particularly affect voters with low political knowledge, while policy arguments will have a larger effect on the highly knowledgeable.

Second, we consider the heterogeneity induced in the electorate by feelings of identification with parties (e.g. Campbell, Converse, Miller, and Stokes 1960; Gerber and Huber 2010; Leeper and Slothuus 2014; Lodge and Hamill 1986) and advance the hypothesis that partisanship acts as a moderator of decision-making. In this case, our expectation is that partisans are less likely to base their vote on the policy content of the constitutional reform, but may take sides pro or against the government and cast their vote accordingly. Extensive literature on affective polarization (Haidt 2013; Hetherington and Rudolph 2015; Iyengar and Westwood 2015) and partisan motivated reasoning (Bolsen, Druckman, and Cook 2014; Lavine, Johnston, and Steenbergen 2012; Leeper and Slothuus 2014; Mullinix 2016; Petersen et al. 2013) indicates that partisans tend to follow their own camp in political decisions. This idea leads to the following hypothesis: 
H3. Independent voters are more likely to vote based on the content of the reform, while partisan voters are more likely to vote following the government heuristic.

With regard to the experimental design, this final hypothesis predicts that policy arguments should have larger effects among independent voters, while the government cue should have larger effects among partisans.

\section{$3 \quad$ Data and research design}

We designed a three-wave panel survey during the period October-December 2016. All interviews were conducted online using the CAWI method, and stratification was used to guarantee the representativeness of the sample with respect to the universe of Italian voters. ${ }^{5}$ Overall, a total of 2,279 respondents took part in the first wave that was conducted about two months before the vote (5-10 October 2016). Between 27 October and 3 November, the respondents were contacted again to take part in the second wave, which included a random assignment to different treatment conditions that were used for the experimental study. The third wave was fielded immediately after the vote, between 9 and 14 December. Due to panel attrition, a total of 1,780 respondents participated in all three waves.

\subsection{Observational analysis: assessing competing theories with Finite Mixture Models}

Evaluating the relative importance of competing theories, such as systematic (H1a) and heuristic (H1b) reasoning, is usually addressed by comparing fit indices from regression models incorporating all theories' predictors. However, when the competing theories are sound, the likely outcome is to observe

\footnotetext{
${ }^{5}$ We stratified the sample based on age, gender, geographical area, educational attainment, and type of employment.
} 
improvements in model fit indices (e.g. AIC reduction) when all predictors are considered, leading to support all-inclusive specifications (Achen 2005). Standard procedure would thus fall short of providing a metric of relative performance that is key in our context. Moreover, the presence of theoretical heterogeneity raises the question of which cases are better explained by each respective theory, and of what explains their heterogeneous applicability (i.e. whether it is political knowledge, $\mathrm{H} 2$, or partisanship, H3).

Finite Mixture Models (FMMs) (Everitt and Hand 1981; Titterington, Smith, and Makov 1985) represent a popular class of models for tackling unobserved heterogeneity: rather than modelling the outcome as a single linear combination of covariates, $y_{i}=a+b x_{i}$, a mixture model allows observations to potentially arise from more than one linear combination of covariates: $y_{i}=\pi_{1} f_{1}(x)+$ $\cdots+\pi_{k} f_{k}(x)$, where $\pi_{k}$ is the proportion of the sample better explained by density function $f_{k}(\cdot)$ (called 'component').

FMMs are often used inductively to estimate the number of latent components, and to let parameters vary across latent groups of observations in order to achieve greater modelling flexibility. However, Imai and Tingley (2012) introduced an FMM approach allowing to specify the components $a$ priori: each component represents a theory of interest, and the quantity $\pi_{k}$, indicating the proportion of observations consistent with theory $k$, offers a direct metric of the relative importance of multiple theoretical accounts. This approach optimally serves our goal of disentangling heuristic reasoning and systematic assessment in voting decisions (H1). Furthermore, FMMs can additionally include concomitant variables to model the probability that individuals belong to either of the two components of the mixture: this allows exploring the factors driving the relative applicability of multiple theories by explicitly introducing theory-predicting covariates. We exploit this feature of FMMs to test the second 
block of hypotheses, considering whether factual knowledge (H2) and partisanship (H3) affect information processing mechanisms.

Model specification. The dependent variable is the actual vote in the referendum, as recalled by respondents in post-referendum Wave $3 .{ }^{6}$ Summary statistics indicate that self-reported votes in our sample (60.6 percent of No votes) closely match the actual referendum outcome (59.1 percent of No votes). All the other variables included in the models (apart from the experimental part) were measured in Wave 1.

We operationalize the government-heuristic theory relying on two established heuristic cues: voters' overall judgement of the performance of the incumbent Renzi government (gov_eval), and the voters' trust in Renzi as prime minister (trust_renzi) $)^{7}$. The systematic-processing theory is operationalized using four indicators of overall agreement with the policy-content of the constitutional reform (syspro1-syspro4) respectively tapping voters' position on four central elements of the reform: the need to 1) change the division of power between the Chamber of Deputies and the Senate, 2) reduce the number of Senators, 3) assign more powers to the central state, and 4) introduce "consultative" referendums. ${ }^{8}$ We therefore consider the following data generating process stemming from two components $(k)$ :

${ }^{6}$ We dropped from the analysis voters that did not turnout and those who cast a blank ballot.

${ }^{7}$ Each item corresponds to a 0-10 scale. The two items correlate substantially (Cronbach's alpha $\left.=0.93\right)$. For question wording and description of the variables, see Appendix F.

${ }^{8}$ We asked the respondents whether they strongly agree, somewhat agree, somewhat disagree, or do not agree at all with each statement. Cronbach's alpha $=0.77$, for question wording, see Appendix F. 


$$
Y_{i} \mid X_{i}, k_{i} \sim f_{k_{i}}\left(Y_{i} \mid X_{i}, \theta_{k_{i}}\right)
$$

where the $\theta_{k_{i}}$ parameters are allowed to differ across the two components, and the individual $i$ is member of the component $k$. We can set $k \in\{G H, S P\}$, i.e. the government-heuristic $(\mathrm{GH})$ and the systematic processing (SP) forms of reasoning, to obtain the following specification:

$$
\begin{aligned}
f_{G H}\left(Y_{i} \mid X_{i}, \theta_{G H}\right) & =\beta_{0}+\beta_{1} \text { gov_eval }_{i}+\beta_{2} \text { trust_renz }_{i}+\boldsymbol{\delta} \boldsymbol{X}+\varepsilon_{i} \\
f_{S P}\left(Y_{i} \mid X_{i}, \theta_{S P}\right) & =\gamma_{0}+\gamma_{1} \text { syspro }_{i}+\gamma_{2} \text { syspro }_{i}+\gamma_{3} \text { syspro }_{i}+\gamma_{4} \text { syspro }_{i}+\boldsymbol{\delta} \boldsymbol{X}+u_{i} \\
\pi_{G H}\left(\phi_{G H}\right) & =\operatorname{logit}^{-1}\left(\delta_{0}\right)
\end{aligned}
$$

where: $\boldsymbol{\beta}$ and $\boldsymbol{\gamma}$ are component-specific parameters, with $\boldsymbol{\beta}$ indicating the parameters for the government-heuristic theory, and $\gamma$ the parameters for the systematic reasoning theory; $\varepsilon_{i}$ and $u_{i}$ are stochastic errors. The matrix $\boldsymbol{X}$ includes the following set of controls: age, gender, education level, selfreported household income, left-right self-placement, and the geographical area of residence. ${ }^{9}$ The corresponding $\boldsymbol{\delta}$ coefficients are constrained to be fixed for both components. The third equation models the probability that each observation is consistent with one of the two theories (via logit link). By indexing the two theories with $k=\{1,2\}$, we can express the likelihood function as follows:

$$
L\left(\Theta, \Pi \mid\left\{X_{i}, Y_{i}\right\}\right)=\prod_{i=1}^{N}\left\{\sum_{k=1}^{2} \pi_{k_{i}} f_{k_{i}}\left(Y_{i} \mid X_{i}, \theta_{k_{i}}\right)\right\}
$$

Where $\pi_{k}$ indicates the population proportion of observations that are generated by theory $k$ and can therefore be interpreted directly as a measure of overall performance of the theory. We can use this proportion to test the first two competing hypotheses: $\mathrm{H} 1 \mathrm{~b}$ (vote decision stemming from government heuristic) will be empirically supported if $\pi_{G H}>\pi_{S P}$ (vice versa for H1a).

\footnotetext{
${ }^{9}$ Summary statistics are available in Appendix B. The full list of items and question wording is in Appendix F.
} 
To test $\mathrm{H} 2$ and $\mathrm{H} 3$ we extend the model to include the two hypothesized theory-predictive variables $^{10}$, factual political knowledge and partisanship. We build the political knowledge index by summing correct answers to 11 factual knowledge questions. ${ }^{11}$ Then, we recast the third equation in model (3) as follows:

$$
\begin{aligned}
f_{G H}\left(Y_{i} \mid X_{i}, \theta_{G H}\right) & =\beta_{0}+\beta_{1} \text { gov_eval }_{i}+\beta_{2} \text { trust_renzi }_{i}+\boldsymbol{\delta} \boldsymbol{X}+\varepsilon_{i} \\
f_{S P}\left(Y_{i} \mid X_{i}, \theta_{S P}\right) & =\gamma_{0}+\gamma_{1} \text { syspro }_{i}+\gamma_{2} \text { syspro }_{i}+\gamma_{3} \text { syspro }_{i}+\gamma_{4} \text { syspro }_{i}+\boldsymbol{\delta} \boldsymbol{X}+u_{i} \\
\pi_{G H}\left(\phi_{G H}\right) & =\operatorname{logit}^{-1}\left(\delta_{0}+\delta_{1} \text { PolitKnow }_{1}\right)
\end{aligned}
$$

The third equation $\left(\pi_{G H}\left(\phi_{G H}\right)\right)$ now models the probability to belong to the government-heuristic theory as a function of the level of political knowledge. The same equation is then re-defined in relation to partisanship to explore the second moderating variable. ${ }^{12}$

\subsection{An experimental test of attribute substitution}

Our observational analysis, designed to tackle theoretical heterogeneity, leaves open the potential for reversed-causality and omitted variable bias. We address these concerns by embedding a set of

${ }^{10}$ In the FMM literature, "moderating" variables affecting the weights of the components on the overall mixture distribution are referred to as "concomitant" variables.

${ }^{11}$ The results hold true when we replace the simple additive index with a Bayesian two-parameter Item Response Theory (IRT) model. This more sophisticated solution estimates items' difficulty parameters - so that wrong answers to easy items count more than wrong answers to difficult ones - and achieves an interval-level measure. The correlation with the additive index is 0.97 .

${ }^{12}$ In this extended model, the interpretation of the mixture differs slightly, since each observation is considered to be a weighted combination of the two theoretical accounts. This feature permits to use these weights $\left(\pi_{m}\right)$ to study under which conditions observations are consistent with a certain theory. 
randomized experimental treatments in the second wave of the panel in order to test the causal effect of a government heuristic cue and policy arguments. In addition, experimental manipulations allow us to detect the direction of these effects on support for the constitutional reform (e.g. does a government cue increase of reduce support for the reform?).

The respondents were randomly assigned to four groups of around 200 participants each. Those assigned to Group 1 and Group 2 received stimuli designed to activate systematic processing: a short argument of around 70 words either in favour of the reform (Group 1) or against the reform (Group 2). We selected the arguments after pilot-testing a larger set of arguments in favour and against the reform using a convenience sample of Italian voters $(\mathrm{N}=121) \cdot{ }^{13}$ Crucially, the respondents read only arguments taken from publicly available sources, which we carefully created based on a content analysis of Italian newspapers and official referendum campaigns' websites. The two stimuli were designed to match the content of two systematic processing items from Study 1 (sysprol and syspro3). The pro argument focused on the improved efficiency of the legislative process. The con argument concerned the issue of the concentration of power that the constitutional reform might have produced. ${ }^{14}$ Those assigned to Group 3 did not read any argument, but were simply reminded of the fact that the reform was "one of the key points of the Renzi government". Thus, this basic manipulation provided the respondents with a simple "government cue" by linking the reform to its main proponent, i.e. the Renzi government. ${ }^{15}$

${ }^{13}$ For further details on the design and the results of the pilot study, see Appendix G.

${ }^{14}$ The precise question wording for all experimental items is available in Appendix F.

${ }^{15}$ As an alternative formulation we could have reminded the respondents that the Prime Minister would have stepped down in case of rejection of the reform. Although this stronger formulation might have yielded larger 
Lastly, the experimental design included a control group, in which the participants simply replied to the outcome question, without neither reading an argument nor receiving a government cue.

Our dependent variable in the experimental analysis is a measure of general support for the constitutional reform on a $0-10$ scale, immediately following the experimental manipulations. This question provides a more fine-grained measure of attitudinal support for the reform than simple voting intentions, and allows us to better capture variation in the response to experimental manipulations.

\section{$4 \quad$ Results}

\subsection{Observational analysis: voting on the government or on the reform?}

We start by examining which decision-making process led Italian voters to either support or oppose the constitutional reform (H1a and $\mathrm{H} 1 \mathrm{~b})$. First, we estimate a set of standard logistic regressions, including: a baseline model, a model with only government-heuristic covariates, one with only systematicassessment covariates, and a full model with both sets of variables. Models include a set of standard socio-demographic covariates (gender, age, education, income, and are of residence), in addition to self-reported left-right placement (models are reported in Table C1 in Appendix C).

The logit models provide evidence for both theories. First, government evaluations and trust in Renzi - as measured in Wave 1 - are found to significantly predict the actual Yes vote, as recalled in Wave 3. Second, three out of four also significantly predicted Yes vote (the introduction of popular initiatives did not predict vote decisions). We then computed the predicted probabilities of Yes vote

effects, it would have mixed two different concepts, i.e. the evaluation of the government and the need for political stability. Thus, we opted for the current, albeit milder formulation. 
from the full regression model including both theories. We find that an average voter with a negative evaluation of the government and low trust in Renzi has a 7 percent probability of voting Yes, while the probability increases to about 75 percent when both variables score high. Similarly, the probability of voting Yes is only 3 percent for an average voter with low agreement with the content of the reform, while it increases to 67 percent for a voter that strongly agrees with the content of the reform. The lowto-high changes are therefore respectively 68 and 64 percentage points, providing a slight lead to the government-heuristic covariates in terms of their ability to predict the vote ${ }^{16}$.

Despite providing relevant evidence for which factors explain actual voting decisions in the constitutional referendum, this model does not allow us to address the question of how many voters are consistent with either theory, because it assumes that both theories predict the vote for all voters (with the consequent risk of overfitting the data). For these reasons, we estimated a Finite Mixture Model with two competing theories (the government-heuristic and the systematic-processing theory) and no theory-predicting variables. ${ }^{17}$ Although our application is theory-driven, we estimated FMM with up to ten latent components, finding that in fact a model with $k=2$ components minimizes both AIC and BIC scores. We assess the two hypotheses through the average posterior proportion $\hat{\pi}_{m}$, indicating the population proportions of observations consistent with each of the two models in the mixture. All

\footnotetext{
${ }^{16}$ Regression tables, plots of the predicted probabilities, and careful explanations for why this standard approach would not address our inferential target are available in Appendix C.
}

${ }^{17}$ We rely on the FLXMRglmfix function in the flexmix R package (Grün and Leisch 2008). The estimation is performed using EM algorithm with various random starting points to avoid potentially local maxima. 
model coefficients are reported in the Appendix D. ${ }^{18}$ The density plot in Figure 1 summarizes the results.

\section{[Figure 1]}

The mixture model indicates that the overall proportion of observations consistent with the government heuristic theory is $67.1 \%$, which in turn means that only $32.9 \%$ of the observations can be accounted by the theory of the systematic assessment of the constitutional reform. This suggests that indeed the 2016 referendum vote was, to a larger extent, a vote about the Renzi government (supporting H1b). A substantial but smaller share of the voters decided how to cast their ballot based on a systematic assessment of the content of the reform. Even if voters adopted both heuristic and systematic forms of reasoning in their voting decisions, attribute substitution, in the form of 'government heuristic', represented the main strategy of decision making.

As an alternative specification, we re-estimated the model using different indicators of systematic processing and find that, again, the majority of votes is better explained by the attribute substitution theory. ${ }^{19}$

${ }^{18}$ Regarding the government-heuristic component, both the overall evaluation of the government and trust in Renzi significantly and substantially correlate with Yes votes. Regarding the systematic-processing component, only the agreement with changing the division of power between the Chamber and the Senate, and the agreement with re-assigning powers to the central state significantly correlate with Yes votes.

19 We replaced the two indicators that are not matched by the experimental manipulations with two alternative indicators of agreement with the content of the reform: agreement with the need to speed up the legislative process and with the need to completely abolish the senate. The results are substantially the same as those presented in the main analysis. 


\subsection{Explaining heuristic and systematic information processing.}

In the second step of the analysis we include theory-predicting covariates to test whether political knowledge and party identification affected voters' attribute substitution. ${ }^{20}$ In the first specification of the model, we use factual political knowledge as theory-predicting variable. Figure 2 illustrates the estimated probability of being consistent with the government-heuristic theory across levels of political-knowledge. ${ }^{21}$

[Figure 2]

The probability to use heuristic processing clearly decreases as political knowledge increases: among the least knowledgeable voters, the probability of being consistent with heuristic reasoning is approximately $70 \%$, while among the most politically sophisticated voters the share drops to about $20 \%$. This finding demonstrates that variation in the level of factual political knowledge can explain a large amount of the heterogeneity in the specific form of reasoning adopted by voters, and supports our expectations that heuristic processing is prevalent among voters with low levels of political knowledge (H2). To provide a more substantial account, we computed that the change in the predicted probabilities of voting Yes passing from low to high values of both components (GH and SA) for

\footnotetext{
${ }^{20}$ The estimated coefficients for the theory-predictive variables are reported in appendix C.

${ }^{21}$ Illustrating the proportions of voters consistent with the systematic processing theory would yield the same results since the two measures sum to one.
} 
voters with low and high political sophistication ${ }^{22}$ : the increase for GH covariates is $+90.1 \%$ in the case of the voters with low political knowledge, and $+94.8 \%$ for voters with high political knowledge. This means that the increase in the predictive ability of GH covariates is only of $4 \%$, comparing knowledgeable to unaware voters. As for systematic assessment variables, the change in the predicted probabilities of voting Yes passing from disapproving to approving the measures contained in the constitutional reform is $+38.7 \%$ for voters with low political knowledge, and $+90.1 \%$ for voters with high political knowledge, resulting in a difference of $51 \%$. We read the larger increase in the predictive ability of SA covariates as reflecting the switch to systematic processing of political information by sophisticated voters.

Next, we focus on the role played by partisanship. We estimate two models including respectively a dummy variable separating independents and pro-government partisans, and a second dummy distinguishing independents and opposition partisans.

[Figure 3]

Results suggest that partisans from both sides are more likely to resort to attribute substitution and vote according to heuristics, although the result is statistically significant only for opposition partisans. In particular, the average probability of being consistent with heuristic processing is $38.5 \%$ for independent voters, while it reaches $43.3 \%$ for partisan voters supporting the government. When the

${ }^{22}$ For all three GH covariates, four SA covariates, and for political knowledge, we set as low (high) value the first (third) quartile. 
same estimate is repeated considering independent voters and supporters of opposition parties, the figures are respectively $34 \%$ and $60 \%$, thus indicating that it is mostly opposition partisans that rely on the evaluation of the government as a heuristic for decision making. ${ }^{23}$ We read evidence presented in Figure 3 as confirming hypothesis H3.

The FMM disentangles the theoretical heterogeneity in the electorate, and clarifies that, far from being rival accounts, systematic processing and attribute substitution are better understood as specific explanations for different types of voters. However, the FMM cannot address the causal antecedence of the two reasoning processes with respect to the vote ${ }^{24}$. For this reason, we resort to experimental data, with the aim to shed light on the causal mechanisms underlying respondents' decision strategies.

\subsection{Experimental results}

Random assignment to treatment conditions in the second wave of the panel allows us to address the potential issues of endogeneity related to previous observational analysis. We first regress the support for the reform on our treatment conditions considering all participants. The results reported in Table 1 indicate that policy arguments do not seem to influence voters, since support for reform does not differ significantly from the control condition in either the pro argument or the con argument condition. Receiving a government cue, however, significantly reduces support for the constitutional reform.

${ }^{23}$ The asymmetry between partisan voters can be explained by the wide difference in the average political knowledge of government (mean=0.43) and opposition partisans (mean=0.25). The variable has mean 0.32 and $\mathrm{sd}=0.74$.

${ }^{24}$ Although observational findings can reflect "true" causal effects, they can also result from spurious omission of a third common cause or depend on the referendum vote (reversed-causality). The most evident source of endogeneity is the rationalization of the support for the reform to accommodate prior political attitudes. 
Although the effect is small (a decrease of six percentage points), we emphasise that the estimate of the government cue is likely to be conservative due to the choice of a very mild manipulation ${ }^{25}$. This result complements the observational analysis, by showing not only a causal effect - i.e. the fact that indeed the governmental sponsor of the reform influenced voters - but also the direction of the effect, since support for the constitutional reform decreased as soon as the reform was associated to the government. If we consider that, according to the FMM results, a majority of voters cast a vote consistent with a government-heuristic model, and that the average evaluation of the government was negative, ${ }^{26}$ it seems plausible that the effect of the government cue is larger than the effects of policy arguments, and is negative (i.e. it reduces support for reform).

[Table 1]

Next, we interacted assignment to treatment conditions with political knowledge in order to test whether the treatments had differential effects depending on the level of knowledge of the respondents. With regard to policy arguments, results show that the effect of reading either a pro or a con argument does not change significantly depending on knowledge levels (see Table E1 in Appendix E). When we focus on the government cue, however, we find that reminding respondents of the "governmental endorsement" of the reform significantly reduces support for reform among those with very low levels

\footnotetext{
${ }^{25}$ By the time we conducted our experiment, most respondents were aware of the government's position on the referendum, while the main pro and con arguments were widely voiced in mainstream and online media. Thus, it is likely that respondents were 'pre-treated' (Slothuus 2016), leading to weak effects.

${ }^{26}$ The average evaluation of the performance of the government was 3.9 on a scale from 0 (completely negative) to 10 (completely positive).
} 
of political knowledge, as illustrated in Graph A of Figure $4 .{ }^{27}$ These results bring partial confirmation to our second hypothesis, by showing that the least-sophisticated group of voters was the most susceptible towards a government heuristic.

[Figure 4]

Lastly, we interacted treatment assignment with the partisan identification of the respondents. Graph B in Figure 4 illustrates the effects of the government cue by whether respondents feel close to a pro-governmental party, an anti-governmental party, or no party at all (independents). Although the government cue does not influence pro-government partisans, we find that support for the constitutional reform decreases significantly among those who identify with an opposition party, which brings partial support to $\mathrm{H} 3$ and confirms our finding from the FMM model: opposition partisans are more likely than both independents and pro-government partisans to use the government cue as a heuristic for decision making on the constitutional reform. Additional findings show that policy arguments influence independents (see Table E2 in Appendix E), thus bringing further support to our expectations (H3).

${ }^{27}$ When we replicate the analysis using an IRT model of political knowledge we obtain very similar results (see Figure E1 in Appendix E). 


\section{Discussion and conclusions}

We set out to answer the question of whether voters in a major European referendum actually voted on the question they were asked. After looking at our results, we must say that a majority of them did not. Instead, they substituted the complex question of reforming their country's constitution with the simpler question of how much they like or dislike the current government. Our heuristic processing hypothesis $(\mathrm{H} 1 \mathrm{~b})$ is empirically prevalent when compared to the systematic processing hypothesis (H1a) - a majority of voters used their evaluation of the current government as a heuristic cue for decision making.

Furthermore, heuristic voting predominates among less informed individuals, which excludes the possibility that heuristic voting is used by well-informed voters as a strategy to either support or sack the government. In addition, we find that heuristic reasoning is more frequent among partisans than among independent voters. The experimental analysis shows a causal effect of our government cue on support for the reform among opposition. This result is in line with recent contributions from political psychology, which show that political decisions are often triggered by automatic processes rooted in strong partisan identities (Haidt 2013; Lodge and Taber 2013).

Our results document the pervasiveness of heuristic reasoning in referendum voting: even in the context of a highly salient reform that implied radical constitutional changes a majority of citizens cast their vote based on their evaluation of the government. Still, a substantial minority of Italian voters - around a third - based their decision on their preferences. This is in line with some recent evidence showing the importance of policy-arguments in direct democracy (Boudreau and McKenzie 2014; Bullock 2011; Anceneaux 2008, 2012). Other studies also conclude that voters are usually well-aware of the substantial arguments of the debate, and that those arguments matter even more than heuristic strategies 
of decision making (Kriesi 2005, Colombo 2016, Colombo and Kriesi 2017). However, most of these studies analysed decisions on single policies and not on complex reform packages, an element that might explain the differences with our results.

How do our own results generalize? In the light of existing evidence, two conditions seem to be particularly important. The first one is the complexity of the issue at stake: the likelihood of attribute substitution increases with issue complexity. Second, we conclude that elite behaviour is crucial in guiding voters' opinion formation in referendums, in line with previous findings on voting in direct democratic consultations (Bowler and Donovan 1998; Kriesi 2005; Lupia 1994; Saris and Sniderman 2004; Slothuus and de Vreese 2010). When heuristic cues are easily available, and elite actors strategically interfere in the process of opinion formation by providing voters with explicit cues, the likelihood of heuristic reasoning increases. By promising to step down in case of a failure of the referendum, the Italian Prime Minister strongly 'cued' voters to decide on his government's faith, instead of the content of the reform. Thus, we believe that future research on direct democracy should explore whether voters adopt different strategies of decision making depending both on the degree of complexity of the ballot proposal, and on the positions taken by political elites.

An open question concerns the extent to which heuristics-based decisions in referendum voting proves normatively desirable. Heuristics may facilitate reaching a 'good decision' (Popkin 1991; Lupia, McCubbins, and Popkin 2000), and in certain contexts have been shown to potentially improve the efficiency of judgements (Gigerenzer and Gaissmaier 2010). However, this is more likely in presence of trusted elites as meaningful signal for voting. In our case, the substitution may undermine the legitimacy of the referendum vote: if voters place more weight on the evaluation of the government than on answering a specific ballot question, how can we know for sure whether voters truly supported or rejected a ballot proposal? The question of whether citizens are competent enough to vote on 
policies is still unsolved. We offer new methodological solutions and call for more research on voters' decision-making mechanisms.

Acknowledgments: We thank Hanspeter Kriesi for contributing to the design of this study and for supporting it financially through an ERC grant (ERC-2013-ADG, GA N N$^{\circ} 338875$ - POLCON); seminar audiences at the European University Institute and at the Department of Political Science, University of Zurich; as well as participants at the University of Rome (February 2017), the EPSA 2017 meetings and two anonymous reviewers for helpful feedback.

\section{Notes on contributors}

Andrea De Angelis is Senior Researcher and Lecturer at the Department of Political Science, University of Lucerne. His research focuses on political behaviour, political methodology, political communication and political psychology. [andrea.deangelis@unilu.ch]

Davide Morisi is Assistant Professor of Political Science at Collegio Carlo Alberto, Turin. His main research interests include public opinion, political behaviour, referendum campaigns, and political psychology. [davide.morisi@carloalberto.org]

Céline Colombo is a Research Associate at the Department of Justice and Home affairs of the Canton of Zurich, Switzerland, and a lecturer in Political Science at the University of Zurich. Her main research interests include political psychology, political behaviour, direct and deliberative democracy [colombo@ipz.uzh.ch] 


\section{References}

Achen, Christopher H. 2005. "Let's Put Garbage-Can Regressions and Garbage-Can Probits Where They Belong." Conflict Management and Peace Science 22(4): 327-339.

Achen, Christopher H, and Larry M Bartels. 2016. Democracy for realists: why elections do not produce responsive government. Princeton, N. J.: Princeton University Press.

Altman, David. 2010. Direct democracy worldwide. Cambridge: Cambridge University Press.

Barabas, Jason, Jennifer Jerit, William Pollock, and Carlisle Rainey. 2014. "The Question(s) of Political Knowledge." American Political Science Review 108(4): 840-855.

Bolsen, Toby, James N. Druckman, and Fay Lomax Cook. 2014. "The Influence of Partisan Motivated Reasoning on Public Opinion." Political Behavior 36(2): 235-262.

Boudreau, Cheryl, and Scott A. MacKenzie. 2014. "Informing the Electorate? How Party Cues and Policy Information Affect Public Opinion about Initiatives." American Journal of Political Science 58(1): 48-62.

Bowler, Shaun, and Todd Donovan. 1998. Demanding Choices: Opinion, Voting, and Direct Democracy. Ann Arbor, MI: University of Michigan Press.

Bullock, John G. 2011. "Elite Influence on Public Opinion in an Informed Electorate." The American Political Science Review 105(3): 496-515.

Campbell, A., P. E. Converse, W. E. Miller, and D. E. Stokes. 1960. The American Voter. Chicago and London: The University of Chicago Press.

Chaiken, Shelly. 1980. "Heuristic versus systematic information processing and the use of source versus message cues in persuasion." Journal of Personality and Social Psychology 39(5): 752766.

Chambers, S. 2001. "Constitutional Referendums and Democratic Deliberation.” In Referendum Democracy, eds. M. Mendelsohn and A. Parkin. London: Palmgrave Macmillan.

Christin, Thomas, Simon Hug, and Pascal Sciarini. 2003. "Interests and information in referendum voting: An analysis of Swiss voters." European Journal of Political Research 41(6): 759-776.

Colombo, Céline. 2016. "Justifications and Citizen Competence in Direct Democracy: A Multilevel Analysis." British Journal of Political Science: 1-20.

Colombo, Céline, and Hanspeter Kriesi. 2017. "Party, policy - or both? Partisan-biased processing of policy arguments in direct democracy." Journal of Elections, Public Opinion and Parties 27(3): 235-253.

Converse, Philip E. 1964. "The nature of belief systems in mass publics." In Ideology and Discontent, ed. David Apter E. , p. 1-74.

Delli Carpini, Michael X., and Scott Keeter. 1996. What Americans know about politics and why it matters. New Haven: Yale University Press.

Druckman, James N. 2015. "Eliminating the local warming effect." Nature Climate Change 5(3): 176177.

Everitt, B. S., and D. J. Hand. 1981. Finite Mixture Distributions. Dordrecht: Springer Netherlands.

Franklin, Mark N., Cees van der Eijk, and Michael Marsh. 1995. "Referendum outcomes and trust in government: Public support for Europe in the wake of Maastricht." West European Politics 18(3): 101-117.

Garry, John, Michael Marsh, and Richard Sinnott. 2005. "“Second-order' versus 'Issue-voting' Effects in EU Referendums: Evidence from the Irish Nice Treaty Referendums." European Union Politics 6(2): 201-221. 
Gerber, Alan S., and Gregory A. Huber. 2010. "Partisanship, political control, and economic assessments.” American Journal of Political Science 54(1): 153-173.

Gigerenzer, Gerd, and Wolfgang Gaissmaier. 2010. "Heuristic Decision Making." Annual Review of Psychology 62(1): 451-482.

Glencross, Andrew, and Alexander Trechsel. 2011. "First or Second Order Referendums? Understanding the Votes on the EU Constitutional Treaty in Four EU Member States." West European Politics 34(4): 755-772.

Grün, Bettina, and Friedrich Leisch. 2008. "FlexMix Version 2: Finite Mixtures with Concomitant Variables and Varying and Constant Parameters." Journal of Statistical Software 28(4).

Haidt, Jonathan. 2013. The righteous mind: why good people are divided by politics and religion. New York: Vintage Books.

Healy, Andrew, and Gabriel S. Lenz. 2014. "Substituting the End for the Whole: Why Voters Respond Primarily to the Election-Year Economy." American Journal of Political Science 58(1): 31-47.

Hetherington, Marc J. 2007. Why trust matters: declining political trust and the demise of American liberalism. Princeton, N.J.: Princeton University Press.

Hetherington, Marc J., and Thomas J. Rudolph. 2015. Why Washington won't work: polarization, political trust, and the governing crisis. Chicago: The University of Chicago Press.

Hobolt, Sara B. 2016. "The Brexit vote: a divided nation, a divided continent." Journal of European Public Policy 23(9): 1259-1277.

Hobolt, Sara B. 2005. "When Europe matters: The impact of political information on voting behaviour in EU referendums." Journal of Elections, Public Opinion and Parties 15(1): 85-109.

Hobolt, Sara Binzer. 2007. "Taking Cues on Europe? Voter competence and party endorsements in referendums on European integration." European Journal of Political Research 46(2): 151-182.

Hug, Simon. 2002. Voices of Europe: citizens, referendums and European integration. Boulder, CO: Rowman \& Littlefield Publishers, Inc.

Imai, Kosuke, and Dustin Tingley. 2012. "A Statistical Method for Empirical Testing of Competing Theories." American Journal of Political Science 56(1): 218-236.

Ivaldi, Gilles. 2006. "Beyond France's 2005 referendum on the European constitutional treaty: Secondorder model, anti-establishment attitudes and the end of the alternative European utopia." West European Politics 29(1): 47-69.

Iyengar, Shanto, and Sean J. Westwood. 2015. "Fear and Loathing across Party Lines: New Evidence on Group Polarization." American Journal of Political Science 59(3): 690-707.

Jerit, Jennifer, Jason Barabas, and Toby Bolsen. 2006. "Citizens, Knowledge, and the Information Environment.” American Journal of Political Science 50(2): 266-282.

Kahneman, Daniel. 2013. Thinking, fast and slow. New York: Farrar, Straus and Giroux.

Kahneman, Daniel, and Shane Frederick. 2002. "Representativeness Revisited: Attribute Substitution in Intuitive Judgment." In Heuristics and Biases, eds. Thomas Gilovich, Dale Griffin, and Daniel Kahneman. Cambridge University Press, p. 49-81.

Kam, Cindy D. 2005. "Who Toes the Party Line? Cues, Values, and Individual Differences." Political Behavior 27(2): 163-182.

Kriesi, Hanspeter. 2005. Direct democratic choice: the Swiss experience. Lanham: Lexington.

Lau, Richard R., and David P. Redlawsk. 2001. "Advantages and Disadvantages of Cognitive Heuristics in Political Decision Making.” American Journal of Political Science 45(4): 951971.

Lavine, Howard G., Christopher D. Johnston, and Marco R. Steenbergen. 2012. The Ambivalent Partisan: How Critical Loyalty Promotes Democracy. Oxford University Press. 
Leduc, Lawrence. 2012. “Opinion change and voting behaviour in referendums.” European Journal of Political Research 41(6): 711-732.

Leeper, Thomas J., and Rune Slothuus. 2014. "Political Parties, Motivated Reasoning, and Public Opinion Formation." Political Psychology 35: 129-156.

Lodge, Milton, and Ruth Hamill. 1986. "A Partisan Schema for Political Information Processing." The American Political Science Review 80(2): 505-520.

Lodge, Milton, and Charles S. Taber. 2013. The rationalizing voter. Cambridge ; New York: Cambridge University Press.

Lupia, Arthur. 1994. "Shortcuts Versus Encyclopedias: Information and Voting Behavior in California Insurance Reform Elections." The American Political Science Review 88(1): 63-76.

Lupia, Arthur, and John G. Matsusaka. 2004. "Direct Democracy: New Approaches to Old Questions." Annual Review of Political Science 7(1): 463-482.

Lupia, Arthur, Mathew D. McCubbins, and Samuel L. Popkin, eds. 2000. Elements of reason: cognition, choice, and the bounds of rationality. Cambridge: Cambridge University Press.

Morisi, Davide. 2016. "Voting under uncertainty: the effect of information in the Scottish independence referendum." Journal of Elections, Public Opinion and Parties 26(3): 354-372.

Mullinix, Kevin J. 2016. "Partisanship and Preference Formation: Competing Motivations, Elite Polarization, and Issue Importance.” Political Behavior 38(2): 383-411.

Petersen, Michael Bang, Martin Skov, Søren Serritzlew, and Thomas Ramsøy. 2013. "Motivated Reasoning and Political Parties: Evidence for Increased Processing in the Face of Party Cues." Political Behavior 35(4): 831-854.

Petty, Richard E., and John T. Cacioppo. 1986. Message Elaboration versus Peripheral Cues. New York: Springer Verlag.

Popkin, Samuel L. 1991. The Reasoning Voter. Chicago: University of Chicago Press.

Reif, Karlheinz, and Hermann Schmitt. 1980. "Nine Second-Order National Elections - a Conceptual Framework for the Analysis of European Election Results." European Journal of Political Research 8(1): 3-44.

Ruth, Saskia Pauline, Yanina Welp, and Laurence Whitehead, eds. 2017. Let the people rule? direct democracy in the twenty-first-century. Colchester: ECPR Press.

Saris, Willem E., and Paul M. Sniderman, eds. 2004. Studies in public opinion: attitudes, nonattitudes, measurement error, and change. Princeton, N.J: Princeton University Press.

Shah, Anuj K., and Daniel M. Oppenheimer. 2008. "Heuristics made easy: An effort-reduction framework." Psychological Bulletin 134(2): 207-222.

Siune, Karen, Palle Svensson, and Ole Tonsgaard. 1994. “The European union: The Danes said 'no' in 1992 but 'yes' in 1995: How and why?" Electoral Studies 13(2): 107-116.

Slothuus, Rune. 2016. "Assessing the Influence of Political Parties on Public Opinion: The Challenge from Pretreatment Effects." Political Communication 33(2): 302-327.

Slothuus, Rune, and Claes H. de Vreese. 2010. "Political Parties, Motivated Reasoning, and Issue Framing Effects." The Journal of Politics 72(3): 630-645.

Sunstein, Cass R. 2005. "Moral heuristics." Behavioral and Brain Sciences 28(4): 531-542.

Svensson, Palle. 2002. "Five Danish referendums on the European Community and European Union: A critical assessment of the Franklin thesis." European Journal of Political Research 41(6): 733750.

Tierney, Stephen. 2012. Constitutional referendums: the theory and practice of republican deliberation. Oxford: Oxford University Press. 
Titterington, D. M., Adrian F. M. Smith, and U. E. Makov. 1985. Statistical analysis of finite mixture distributions. Chichester: Wiley.

Trechsel, Alexander H. 2006. "Curing democracy's ills? Modern technology and democratic procedures." In Réflexions sur l'avenir de la démocratie en Europe.: contributions à la conférence l'avenir de la démocratie en Europe" Projet intégré "les institutions démocratiques en action", 17-19 novembre 2004, Barcelone., ed. Directorate General of Political Affairs Council of Europe. Strasbourg: Conseil de l'Europe.

Zaller, J. R. 1992. The nature and origins of mass opinion. Cambridge: Cambridge university press. 
Table 1. Average treatment effects (all respondents)

Support for the constitutional reform

(1)

(2)

Treatment groups (ref: control)

- Pro argument

0.015

0.018

$(0.034)$

(0.034)

- Con argument

$-0.007$

$-0.007$

$(0.033)$

(0.033)

- Govt. cue

$-0.060^{*}$

$-0.060 *$

$(0.034)$

$(0.035)$

Demographics (age, gender, education)

No

Yes

Constant

$0.466^{* * *}$

$0.424 * * *$

(0.023)

(0.058)

$\mathrm{R}^{2}$

.003

.009

$\mathrm{N}$

828

826

Note: Table entries are OLS coefficients with standard errors in parentheses. Dependent variable: support for constitutional reform from 0 (minimum) to 1 (maximum).

$* \mathrm{p}<0.1, * * \mathrm{p}<0.05, * * * \mathrm{p}<0.01$ 
Figure 1. Density plot of estimated probability of observations of being consistent with GH and SA theory

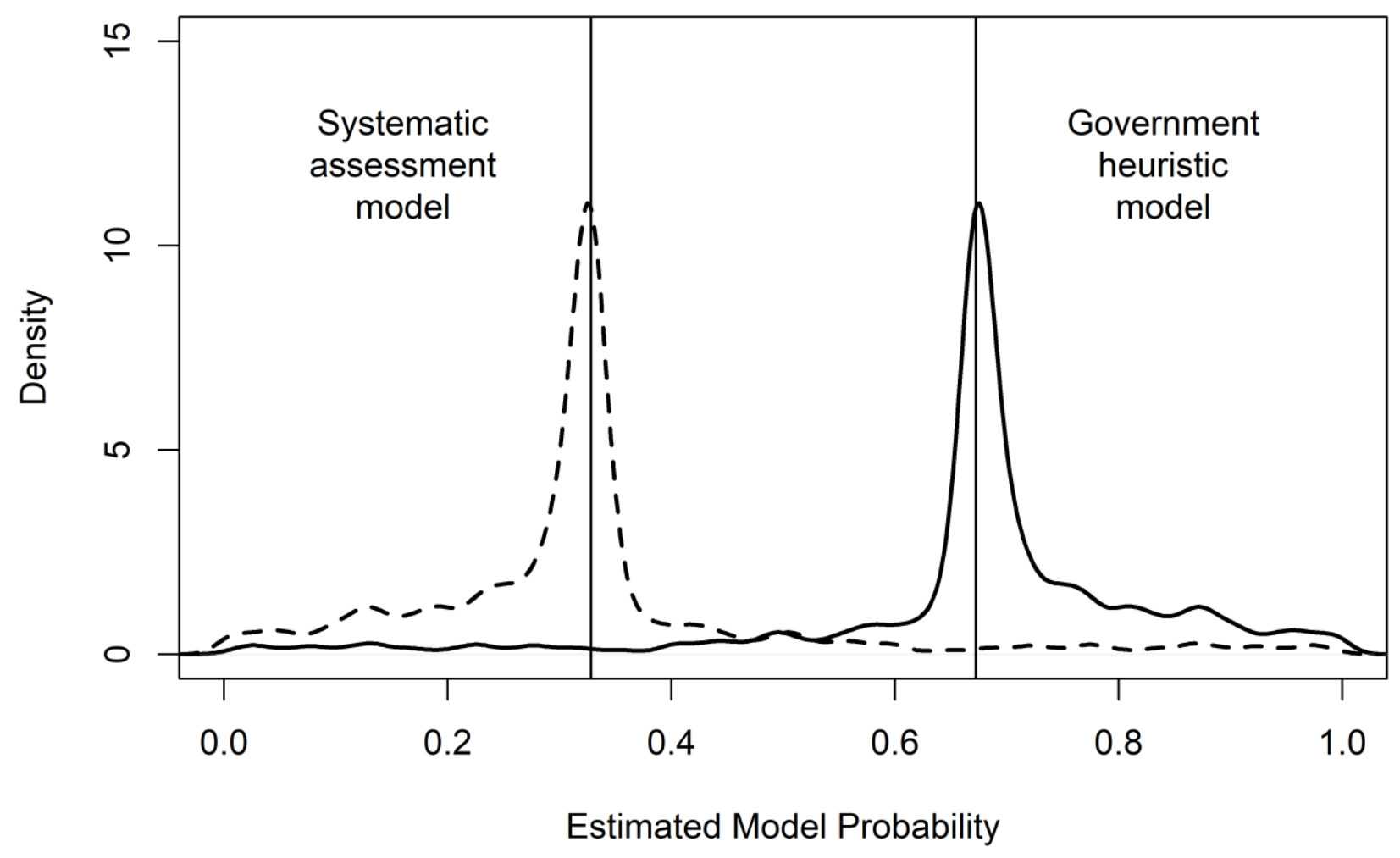

Note: the plot represents the estimated probabilities that each observation is consistent with theory m. Vertical lines represent the overall performance of each theory. 
Figure 2. Estimated probability of observations being consistent with GH and SA theory as a function of political knowledge

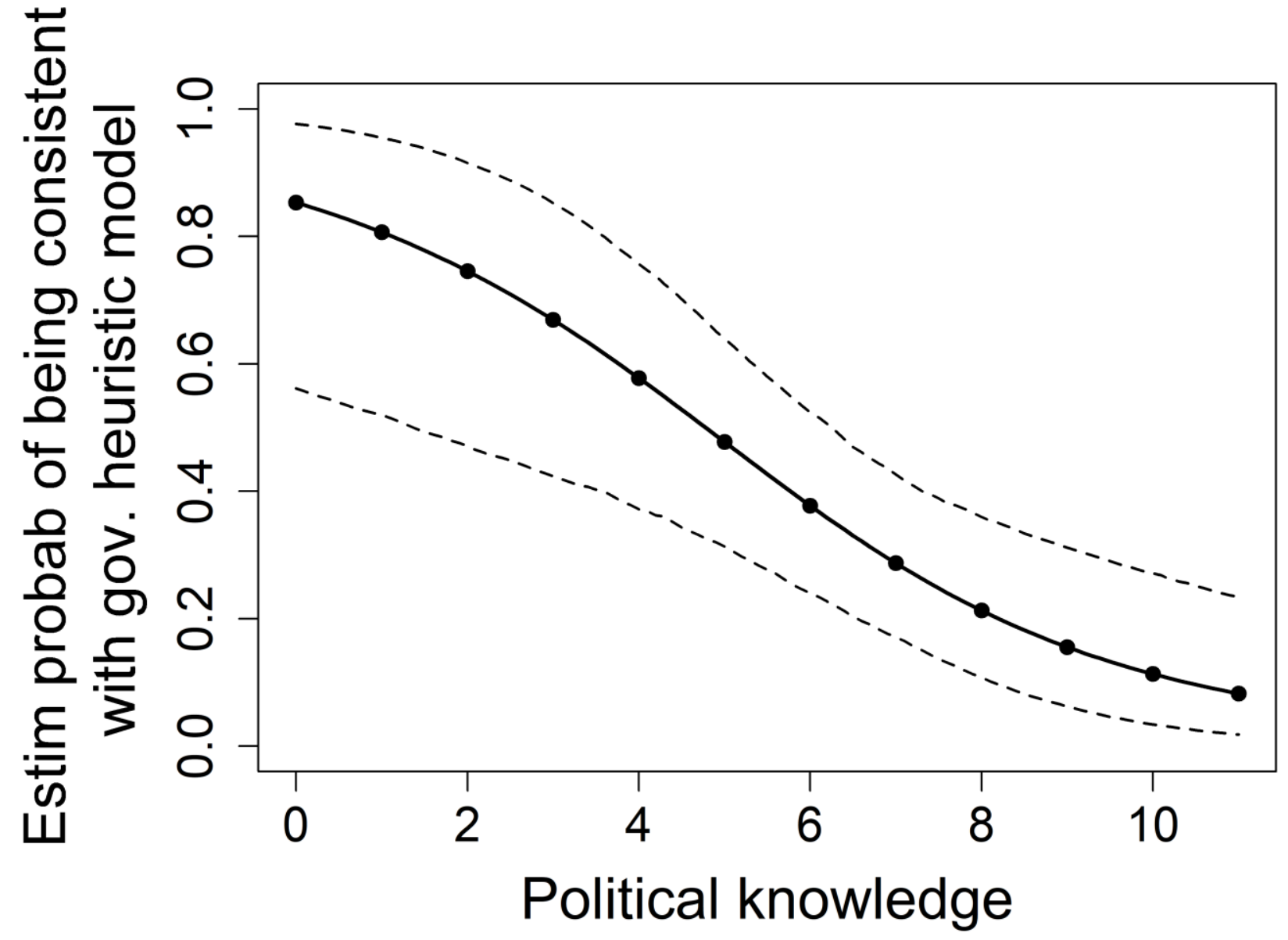

Note: the circles represent the estimated probabilities that each observation is consistent with theory $m$, reported with the $95 \%$ confidence intervals (computed via Monte Carlo approximation). 
Figure 3. Estimated probability of observations being consistent with GH theory as a function of partisanship
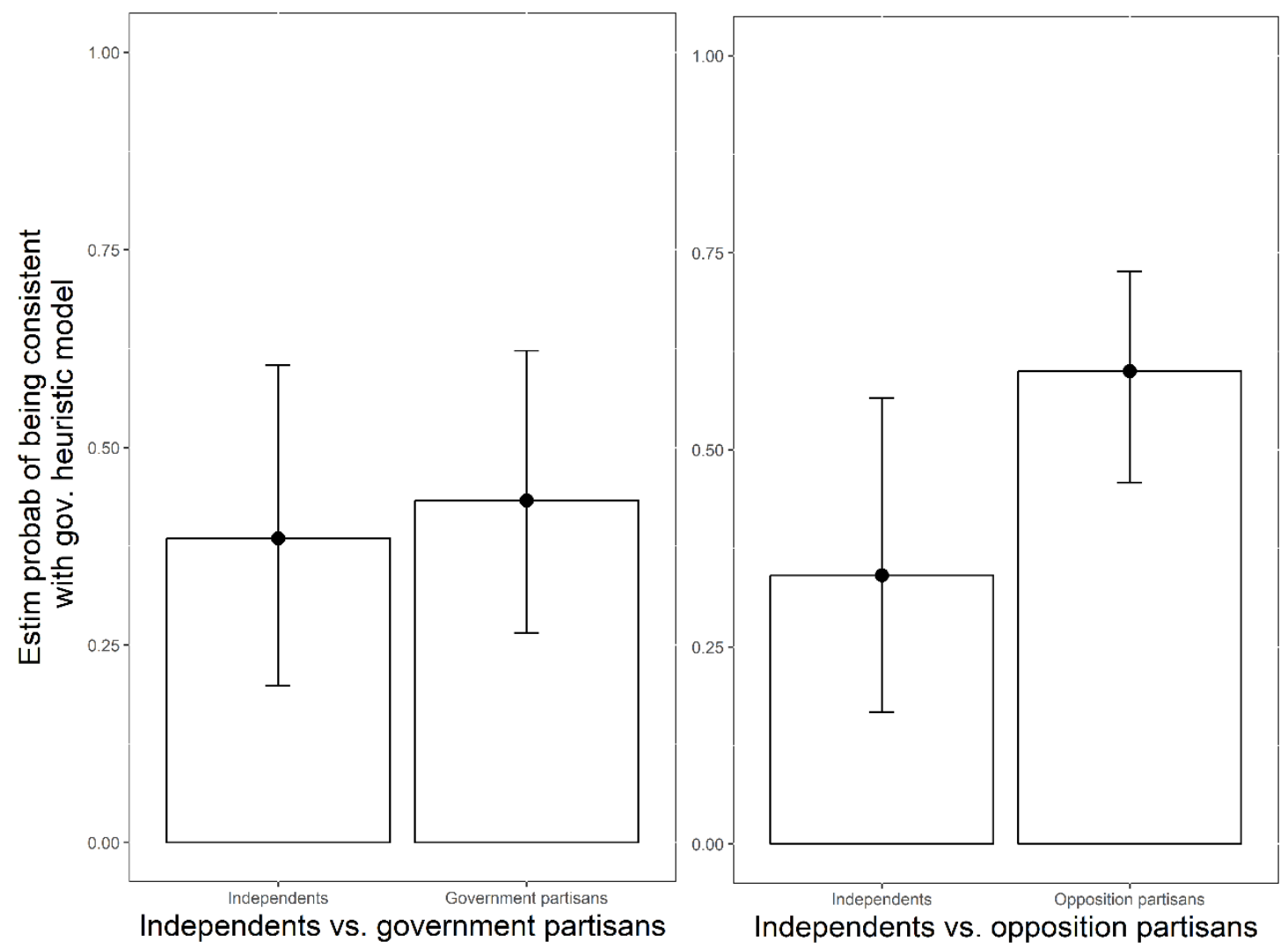

Note: the circles represent the estimated probabilities that each observation is consistent with theory $m, \zeta_{i, m}$, reported with the $95 \%$ confidence intervals (computed via Monte Carlo approximation). The left side refers to the comparison of independents and pro-government partisans, while the right side refers to the comparison of the independents with the opposition partisans. The slight difference in the estimated proportions for the "independents" category depends on the fact that the analysis is performed on two different samples. 
Figure 4. Effects of government cue by political knowledge and partisanship

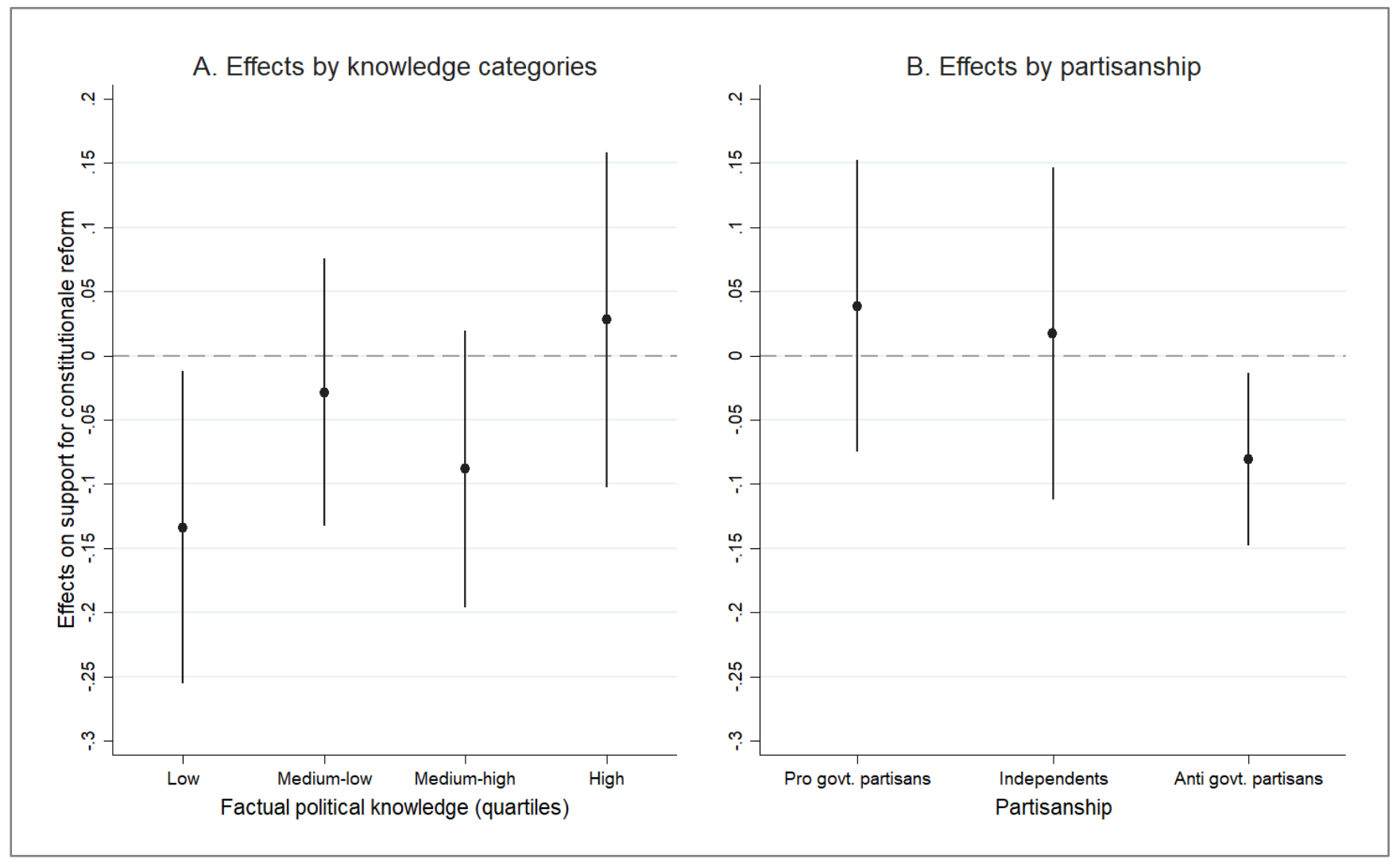

Note: marginal effects of exposure to government cue compared to control group (value 0 on the Y-axis).

Calculations based on OLS regressions (Plot A: Model 1 in Table E1, Plot B: Model 1 in Table E2 in Appendix E). Vertical bars correspond to $90 \%$ confidence intervals. 